\title{
Effect of abrasive particle size on tribochemical wear of monocrystalline silicon
}

Peng Zhang ${ }^{\mathrm{a}}$, Hongtu He ${ }^{\mathrm{b}}$, Cheng Chen ${ }^{\mathrm{a}}$, Chen Xiao ${ }^{\mathrm{a}}$, Lei Chen ${ }^{\mathrm{a}}$, and Linmao Qian ${ }^{\mathrm{a} *}$

\begin{abstract}
Using atomic force microscopy, the nanowear of hydrogen-terminated silicon surface was investigated in water with spherical $\mathrm{SiO}_{2}$ tips. The radii of tips can significantly affect the material removal of silicon surface and large tip could result in substantial wear and high friction force. Analysis suggests that the increase in contact area could enhance the tribochemical reaction by forming more $\mathrm{Si}-\mathrm{O}-\mathrm{Si}$ bonding bridges at $\mathrm{Si} / \mathrm{SiO}_{2}$ interface. Thus, for the tribochemical wear of silicon under elastic contact condition, the abrasive particle size dependence of material removal was more attributable to the change of contact area than to the change of indentation volume. These results may help gain a profound insight into the influence of abrasive particle size on tribochemical wear of silicon.
\end{abstract}

Keywords: Silicon, Tribochemical Wear, Tip radius, Contact area 


\section{Introduction}

Chemical mechanical planarization (CMP) has been widely used to remove excessive materials and achieve atomic-level smooth surface during fabrication of Si-based integrated circuits [1]. Generally, the CMP process of silicon involves the mechanical effect by abrasive particles and the chemical effect of polishing surroundings (e.g., oxidation, passivation, dissolution, and corrosion). Thus, material removal of silicon surface is usually considered a typical tribochemical process [2]. Given that the CMP process is a result of material removal by massive abrasive particles in the slurry, the macroscopic CMP models usually assume that each abrasive particle produces the same effect on the surface of material $[3,4]$. However, during the actual CMP process, the abrasive particle size and the applied force of each particle on wafer surface change randomly and are difficult to be measured accurately. Therefore, to reveal the mechanism of microscopic material removal in CMP process, it is of great importance to understand the effect of abrasive particle size on the material removal of silicon surface at atomic scale.

Several experimental results and empirical models show that the efficiency of material removal and quality of wafer surfaces are significantly influenced by the process parameters of CMP, such as the shape and size of abrasive particles, down pressure, velocity, $\mathrm{pH}$, and particle concentration of slurry [5-7]. Numerous studies have reported that particle sizes play a critical role in controlling the rate of material removal in a CMP abrasive procedure [8-13]. Many of these studies support that an increase in abrasive particle size enhances the rate of material removal. For example, 
Lee et al. [8] conducted the $\mathrm{SiO}_{2} \mathrm{CMP}$ experiments using the slurries with various sizes of $\mathrm{SiO}_{2}$ particles, and their results found that the rate of material removal increases with the increase in particle size. Tamboli et al. [9] achieved similar experimental results for the CMP process of tantalum and tetraethyloxysilane films using silica slurries. These research results are often explained by the indentation volume model [14]. During the CMP process, a "softened layer" forms on wafer surface through chemical reaction with the active component in polishing slurry and is then removed mechanically by the plastic deformation induced by abrasive particles $[8,15]$. Therefore, the material removal of single particle can be viewed as a plasticity-indentation sliding process [16]. Based on this theory, one can expect that for given a constant down pressure, large abrasive particles can induce large indentation volume and substantial material removal rate.

On the contrary, some other experimental results indicated that the material removal decreases with the increase in abrasive particle size [10]. For example, the experimental results on polishing process of tungsten by $\mathrm{Al}_{2} \mathrm{O}_{3}$ particles demonstrated that the rate of material removal increases substantially with decreasing particle size [12]. Lu et al. [17] achieved similar experimental results for the polishing of $\mathrm{Cu}$ and Ta discs with silica slurries. These results are usually explained by the contact area model [11]. For fixed slurry weight or volume, the decrease in particle size causes a linear increase in the number of particles along with the increase in the total effective contact area. The increase in effective contact area enhances the kinetics of the 
chemical reaction by assisting the removal of the chemically modified layer from the wafer surface [12].

Material removal based on CMP is usually a coupling result of multiple influencing factors because of the complex chemical and mechanical interactions at the wafer-slurry-pad interface. Although two dominant models have been proposed to explain the difference in CMP results, the size effect of abrasive particle is still unclear because different experimental conditions and theoretical hypotheses have been employed. Generally, two types of conditions had been employed to study the size effect of abrasive particles: (a) variation of particle size for a constant particle concentration, and (b) variation of particle size for a constant particle loading by weight or volume [9]. In the condition (b), since the number of abrasive particles may vary with particle size, it is difficult to clarify the size effect of particles. Moreover, the theoretical hypotheses were also different in kinds of CMP models. For example, based on the assumption of normal distribution of abrasive size and regularly periodic pad topography, Luo and Dornfeld [3] reported that the number of active abrasives increases as the particle size increases. As a comparison, after assuming uniform particle size and normal distribution of asperity height on pad surface, Jeng and Huang [4] indicated that the number of active abrasives decreases rapidly as the particle size increases. These differences in the number of active abrasives may further induce different particle size effect. Therefore, through a single-asperity sliding wear test, more intuitive and reliable results can be achieved to radically confirm the mechanism of abrasive particle size effect in tribochemical wear process. 
of silicon surface was studied by rubbing against spherical $\mathrm{SiO}_{2}$ tips with various radii in water. The tribochemical wear mechanism was investigated by transmission electron microscope analysis of the wear area. The indentation volume model and the contact area model were verified from a material removal mechanism perspective. The present work can help clarify the size effect of abrasive particle in tribochemical wear process.

\section{Material and methods}

\subsection{Materials}

A p-doped Si(100) wafer was purchased from MEMC Electronic Materials, Inc., USA. A native oxide layer of approximately $0.5 \mathrm{~nm}$ thickness was detected on the silicon surface by Auger electron spectroscopy (PHI700, ULVAC-PHI, Japan) [18]. The immediately polishing silicon surface is reported to be predominantly terminated by hydrogen without oxide layer [19]. In order to be closer to the actual CMP dynamic process, hydrogen-terminated silicon ( $\mathrm{Si}-\mathrm{H})$ surface was used for nanowear tests, which was achieved by dipping in $20 \%$ diluted hydrofluoric acid for 2 min [20]. The root mean square roughness of the Si-H surface was $0.1 \mathrm{~nm}$ over a $500 \times 500 \mathrm{~nm}^{2}$ area by an atomic force microscope (AFM, SPI3800N, Seiko, Japan). Spherical $\mathrm{SiO}_{2}$ tips (Novascan Technologies, Ames, IA, USA) with various radii $R$ of $0.32,1.2$, and $2.8 \mu \mathrm{m}$ were used as the counter-surfaces for the nanowear tests (Fig. 1). The normal spring constants of the cantilevers were calibrated at approximately $28 \mathrm{~N} / \mathrm{m}$ by thermal noise method using an MFP-3D ${ }^{\mathrm{TM}}$ AFM (Asylum Research, CA) [21]. The 
pure water with $18.2 \mathrm{M} \Omega \cdot \mathrm{cm}$ resistivity was obtained from a water purification apparatus (Master-S, Hi-tech, China).

\subsection{Test methods}

Using an environment-controlled atomic force microscope (AFM), the nanowear tests were performed in pure water at ambient temperature using an area-scanning mode. As illustrated in Fig. 1(a), the spherical $\mathrm{SiO}_{2}$ tip moved equidistantly on the silicon surface under a normal load $F_{n}$. The scanning area was $2 \mu \mathrm{m} \times 2 \mu \mathrm{m}$, the sliding velocity was $4 \mu \mathrm{m} / \mathrm{s}$, and the line interval of scanning was set at $15.6 \mathrm{~nm}$. After the wear tests, the topography of wear marks was characterized with the silicon nitride tip (curvature radius $=20 \mathrm{~nm}$; spring constant $=0.1 \mathrm{~N} / \mathrm{m} ;$ MLCT, Veeco, USA).

\subsection{Observation of TEM}

To observe the lattice characteristic and microstructure of wear region on the silicon surface, a wear mark was produced using a 1.2- $\mu \mathrm{m} \mathrm{SiO}_{2}$ tip on $\mathrm{Si}-\mathrm{H}$ surface in pure water. The cross sectional TEM sample was prepared by a focused ion beam miller (FIB, Nanolab Helios 400S, FEI, Holland). Prior to milling, an epoxy polymer was deposited on the manufactured silicon sample surface as the passivation layer to avoid the damage of silicon surface. The cross section of the wear mark was characterized by a high-resolution transmission electron microscope (HRTEM, Tecnai G2 F20, FEI, USA).

\section{Results}

\subsection{Effect of abrasive particle size on wear of $\mathrm{Si}-\mathrm{H}$ surface}


To investigate the effect of abrasive particle size on the material removal of silicon surface, the nanowear tests in water were carried out on $\mathrm{Si}-\mathrm{H}$ surface using spherical $\mathrm{SiO}_{2}$ tips with various radii. Fig. 2 displays the AFM images and characteristic line profile of wear marks. Given that the applied normal load $F_{n}$ varied from $0.875 \mu \mathrm{N}$ to $5.25 \mu \mathrm{N}$, the corresponding maximum DMT contact pressure $P_{\max }$ was estimated as $\sim 3 \mathrm{GPa}$, which was significantly less than the yield limit ( $\sim \mathrm{GPa}$ ) of monocrystalline silicon [22]. Although the contact between $\mathrm{SiO}_{2}$ and $\mathrm{Si}$ surface is elastic, the silicon surface exhibit permanent material removal. The results imply that the nanowear of silicon should be a synergy of mechanical effect and chemical reactions.

The average depth and volume of the wear marks are plotted as the functions of applied normal load in Fig. 3. As the applied normal load $F_{n}$ increased from $0.875 \mu \mathrm{N}$ to $5.25 \mu \mathrm{N}$, the wear depth $d$ increased from $0.2 \mathrm{~nm}$ to $0.4 \mathrm{~nm}, 0.3 \mathrm{~nm}$ to $0.75 \mathrm{~nm}$ and $0.6 \mathrm{~nm}$ to $1.4 \mathrm{~nm}$ when a spherical $\mathrm{SiO}_{2}$ tip of $0.32 \mu \mathrm{m}, 1.2 \mu \mathrm{m}$ and $2.8 \mu \mathrm{m}$ radius was used respectively. The wear volumes $V$ presented the same variation trend, that is, for a given normal load, the large tip caused severe wear, while for a given tip radius, the wear depth and wear volume of silicon surface also increase as the increase of normal load. These results imply that both abrasive particle size and applied normal load can significantly affected the material removal of silicon. Moreover, as shown in the inset in Fig. 3(b), large tip can produce severe wear even at low contact pressure, which suggests that mechanical interaction may not be the dominant factor in determining material removal rate. According to the macro CMP model, the material removal of 
silicon may be related to the indentation volume or contact area between the abrasive particle and silicon surface $[4,23]$. However, with the increase in the applied normal load, both the indentation volume and contact area between the spherical $\mathrm{SiO}_{2}$ tip and silicon surface increased simultaneously. Which of the two parameters plays an important role in the material removal of silicon needs further clarification.

\subsection{Effect of abrasive particle size on friction of $\mathrm{Si}-\mathrm{H} / \mathrm{SiO}_{2}$ pair}

To understand the effect of abrasive particle size on friction of $\mathrm{Si}-\mathrm{H} / \mathrm{SiO}_{2}$ pair, the friction force was measured as a function of normal load during wear tests. As shown in Fig. 6(a), when the applied load $F_{n}$ increased from $0.875 \mu \mathrm{N}$ to $5.25 \mu \mathrm{N}$, the friction force $F_{t}$ increased from $52 \mathrm{nN}$ to $270 \mathrm{nN}, 160 \mathrm{nN}$ to $575 \mathrm{nN}$ and $257 \mathrm{nN}$ to $915 \mathrm{nN}$ when a spherical $\mathrm{SiO}_{2}$ tip of $0.32 \mu \mathrm{m}, 1.2 \mu \mathrm{m}$ and $2.8 \mu \mathrm{m}$ radius was used respectively. The friction force was nearly proportional to the applied load for various tips. For a given normal load condition, the large tip led to high friction force.

Material removal amount usually depends on the energy dissipated through the contact sliding [24, 25]. The dissipated energy $E$ is the integration of the friction force $F_{t}$ over the total sliding distance [26]. The function curve between the cumulative dissipated energy and material removal amount is plotted in Fig. 6(b). The wear volume increased nearly linearly with the cumulative dissipated energy. Moreover, regardless of the tip radius, a similar wear volume will dissipate almost the same friction energy. This result suggests that the material removal of Si-H surface was highly dependent on the frictional energy dissipation in wear process.

\subsection{HRTEM observation on wear area of $\mathrm{Si}-\mathrm{H}$ surface}


To clear the wear mechanism of the $\mathrm{Si}-\mathrm{H} / \mathrm{SiO}_{2}$ pair in water, an HRTEM was employed to observe the cross section of the wear area of silicon surface. As shown in Fig. 4(a), the AFM image and characteristic line profile of a wear scar shows that the depth and width of the wear scar were 3.8 and $72 \mathrm{~nm}$. This result is consistent with the result of TEM observation in Fig. 4(b). Fig. 4(c) shows a magnified layer structure and stair-stepping characteristic in the wear boundary. Under a contact pressure of $0.988 \mathrm{GPa}$, about 14 layers of silicon atoms were removed after 50 sliding cycles on $\mathrm{Si}-\mathrm{H}$ surface in water. No discernable dislocations or defects in the subsurface silicon lattice were observed. The absence of fracture or plastic deformation indicated that the material removal of silicon surface was mainly attributed to the tribochemical reaction.

\section{Discussion}

\subsection{Tribochemical wear mechanism of $\mathrm{Si}-\mathrm{H} / \mathrm{SiO}_{2}$ pair in water}

Previous studies suggested that the chemical property of two solid surfaces and humidity of environment significantly affect the tribochemical process of $\mathrm{Si} / \mathrm{SiO}_{2}$ pair $[22,27,28]$. In liquid water, the tribochemical reaction can be similar or severe on $\mathrm{Si}-\mathrm{H}$ surface. As shown in Fig. 5, a replacement of surface $\mathrm{Si}-\mathrm{H}$ by $\mathrm{Si}-\mathrm{OH}$ could occur continuously on the silicon surface in liquid water [29]. Because of the hydrolysis of $\mathrm{SiO}_{2}$ network, the top surface of the $\mathrm{SiO}_{2}$ tip also contains a high concentration of hydroxyl groups $[30,31]$. The dehydration and condensation reactions could then occur between two hydroxyl groups of $\mathrm{Si}$ surface and $\mathrm{SiO}_{2}$ tip, thereby resulting in the formation of the Si-O-Si bridges across the sliding interface [18, 19]. The interfacial 
siloxane bond could be strained because of compressing and shearing, which could further facilitate the hydrolysis reaction to break the Si-Si backbonds of the silicon surface [32]. The surface Si atom could be removed as silica acid species dissolved in aqueous solution or transferred during sliding [33]. Therefore, the formation of interfacial siloxane bond plays a crucial role in tribochemical reaction and its quantity decides the material removal efficiency to a great extent. In the next section, the effect of abrasive particle size on the tribochemical removal of silicon will be discussed in detail on the basis of the calculation of indentation volume and contact area.

\subsection{Effect of elastic indentation volume on the tribochemical wear of silicon}

Fig. 3 clearly shows that abrasive particle size significantly affected the wear of $\mathrm{Si}-\mathrm{H}$ surface in water. The large tip could cause severe wear and high friction force at the same loading condition. However, with the increase in tip radius, both the indentation volume and contact area between the tip and silicon surface changed simultaneously. Therefore, to clarify which of these parameters primarily determined the amount of material removal, the effect of indentation volume (or contact area) on wear volume should be individually analyzed by choosing the data points with representativeness.

In the experiments, only tiny wear occurred on the surface of $\mathrm{SiO}_{2}$ tips and the change of tip radius during contact sliding was negligible. Therefore, the contact of tip and substrate can always be regarded as an ideal sphere-flat elastic contact under an area-scanning mode. Based on DMT contact theory [34], the contact area $A$ and indentation volume $V_{i}$ can be calculated. Fig. 7(a) shows the variation of indentation 
volume with contact area at various applied loads using three kinds of tips with different sizes. As shown in inset of Fig. 7(a), data points A and B exhibited nearly equal contact areas, but point B showed a larger indentation volume than that in point A. Here, point A was obtained by using a $1.2-\mu \mathrm{m} \mathrm{SiO}_{2}$ tip at a load of $0.875 \mu \mathrm{N}$, and point $\mathrm{B}$ was obtained by using a $0.32-\mu \mathrm{m} \mathrm{SiO}_{2}$ tip at a load of $3.5 \mu \mathrm{N}$. Therefore, data points $\mathrm{A}$ and $\mathrm{B}$ were selected to analyze the effect of indentation volume on the material removal of silicon surface. As shown in Fig. 7(b), when the indentation volume increased 3.87 times (from $96.7 \mathrm{~nm}^{3}$ to $374 \mathrm{~nm}^{3}$ ), the corresponding wear volume multiplied by only 1.56 times (from $1.01 \times 10^{6} \mathrm{~nm}^{3}$ to $1.58 \times 10^{6} \mathrm{~nm}^{3}$ ). This result suggests that a large indentation volume could result in severe wear during the tribochemical wear process at elastic deformation condition. Nevertheless, the traditional indentation volume model suggests that the rate of material removal is proportional to the plastic indentation volume of abrasive particle [8]. Compared with the traditional plastic indention volume model, the wear volume showed a relatively weak dependence on indentation volume under the elastic deformation condition.

The results in Fig. 7 show that a large indentation depth could result in severe wear under the same contact area condition. For a completely elastic contact, a deep indentation is originated from large contact stress. In the present experiments, the vertical deformation depth could be estimated at less than $0.5 \mathrm{~nm}$, which corresponds to $\sim 2 \mathrm{Si}$ atomic layers. The mechanical interaction alone was insufficient for the $\mathrm{Si}$ atom removal from the substrate surface. Instead, the tribochemical reaction induced by interfacial bonding effects can enhance the material removal of silicon surface via 
the formation of interfacial siloxane bond [32]. Therefore, the effect of elastic indentation volume on material removal rate may be attributed to the facilitation of contact pressure to the tribochemical reaction $[24,35]$.

\subsection{Effect of contact area on the tribochemical wear of silicon}

To further understand the effects of abrasive particle size in the tribochemical wear process of silicon, the dependence of the wear volume $V$ on the contact area $A$ of Si-H surface in water was analyzed. As shown in Fig. 8(a), data points C and D were also chosen for studying the effect of contact area on material removal. Here, data point $\mathrm{C}$ was obtained by using a $1.2-\mu \mathrm{m} \mathrm{SiO}_{2}$ tip at a load of $4.375 \mu \mathrm{N}$, and data point D was obtained by using a $2.8-\mu \mathrm{m} \mathrm{SiO}$ tip at a load of $3.5 \mu \mathrm{N}$. Points $\mathrm{C}$ and $\mathrm{D}$ exhibited nearly equal indentation volume, but point $\mathrm{D}$ showed a large contact area (inset in Fig. 8(a)). As shown in Fig. 8(b), when the contact area increased to $~ 1.526$ times (from $58.9 \times 100 \mathrm{~nm}^{2}$ to $89.9 \times 100 \mathrm{~nm}^{2}$ ), the corresponding wear volume multiplied by $\sim 1.316$ times (from $3.61 \times 10^{6} \mathrm{~nm}^{3}$ to $4.75 \times 10^{6} \mathrm{~nm}^{3}$ ). The two ratios were quite close, indicating an approximate linear relationship between wear volume and contact area. Therefore, the efficiency of material removal might depend mainly on the contact area between $\mathrm{SiO}_{2}$ tip and silicon surface under the same indentation volume condition.

This result is consistent with the contact area mechanism of the macroscopic CMP model. According to the tribochemical reaction mechanism of silicon induced by bonding effects, the formation of Si-O-Si bonding bridges between two solid surfaces and its amount can directly determine the occurrence of tribochemical 
reaction and the removal efficiency of surface silicon atoms [27, 32]. The increase in contact area can facilitate the formation of the Si-O-Si bonding bridges between two solid surfaces. With the movement of $\mathrm{SiO}_{2}$ tip, the $\mathrm{Si}-\mathrm{Si}$ backbonds of silicon surface were broken and the topmost $\mathrm{Si}$ atoms were removed. Therefore, the material removal volume depended mainly on the contact area between silica tip and silicon surface.

In summary, the effect of indentation volume on the rate of material removal was relatively weak under the elastic deformation condition, whereas the effective contact area of $\mathrm{Si}$ substrate/ $\mathrm{SiO}_{2}$ tip almost played a decisive role on the material removal efficiency of silicon. Under the same loading condition, a large abrasive particle could result in substantial material removal due to larger contact area along with the greater number of interfacial siloxane bond at $\mathrm{Si} / \mathrm{SiO}_{2}$ interface. The size effect of abrasive particles was attributed mainly to the variation of contact area for the tribochemical wear of silicon. Therefore, to improve the rate of material removal in the CMP process, especially under ultra-low down pressure, the maximum effective contact area between abrasives and wafer should perhaps be ensure in selecting the proper abrasive particle size.

\section{Conclusion}

Using atomic force microscopy, the wear tests for $\mathrm{Si}-\mathrm{H}$ surface were conducted by spherical $\mathrm{SiO}_{2}$ tips with various radii in water. The main conclusions can be summarized as follows:

(1) The experimental results present a significant effect of abrasive particle size on material removal of silicon surface, indicating that large tip can cause severe wear 
and high friction force due to larger contact area along with the greater number of interfacial siloxane bond at $\mathrm{Si} / \mathrm{SiO}_{2}$ interface. The HRTEM observation confirms that the material removal of $\mathrm{Si}-\mathrm{H}$ surface in water was a typical tribochemical process.

(2) For constant contact area, when the indentation volume increases almost 4 times, the wear volume only increases 1.5 times. An increase in indentation volume can facilitate tribochemical wear under elastic deformation condition. However, the effect is insignificant compared with the traditional plastic indentation volume model of CMP.

(3) For constant indentation volume, when the contact area increases to 1.5 times, the wear volume increases 1.3 times. The wear volume of silicon surface was nearly proportional to the contact area. Therefore, for the tribochemical wear of silicon under low load, the effect of abrasive particle size on material removal efficiency is more attributable to the variation of contact area than to the change of indentation volume.

\section{Acknowledgements}

This work was supported by the National Natural Science Foundation of China (Grant no. 51527901, 91323302, and 51375409). HH was supported by the National Science Foundation of China (Grant no. 51605401).

\section{References}

[1] Zantye PB, Kumar A, Sikder AK. Chemical mechanical planarization for microelectronics applications. Mat Sci Eng R. 2004;45:89-220.

[2] Oh S, Seok J. An integrated material removal model for silicon dioxide layers in chemical mechanical polishing processes. Wear. 2009;266:839-49. 
[3] Luo JF, Dornfeld DA. Material removal mechanism in chemical mechanical polishing: Theory and modeling. IEEE Trans Semiconduct Manufact. 2001;14:112-33.

[4] Jeng YR, Huang PY. Impact of abrasive particles on the material removal rate in CMP - A microcontact perspective. Electrochem Solid St. 2004;7:G40-G3.

[5] Wang Y, Zhao YW, Chen X. Chemical mechanical planarization from macro-scale to molecular-scale. Mater Manuf Process. 2012;27:641-9.

[6] Guoshun P, Ning W, Hua G, Yan L. An empirical approach to explain the material removal rate for copper chemical mechanical polishing. Tribol Int. 2012;47:142-4.

[7] Forsberg M. Effect of process parameters on material removal rate in chemical mechanical polishing of Si(100). Microelectron Eng. 2005;77:319-26.

[8] Lee HS, Jeong HD, Dornfeld DA. Semi-empirical material removal rate distribution model for $\mathrm{SiO}_{2}$ chemical mechanical polishing (CMP) processes. Precis Eng. 2013;37:483-90.

[9] Tamboli D, Banerjee G, Waddell M. Novel interpretations of CMP removal rate dependencies on slurry particle size and concentration. Electrochem Solid St. 2004;7:F62-F5.

[10] Xie YS, Bhushan B. Effects of particle size, polishing pad and contact pressure in free abrasive polishing. Wear. 1996;200:281-95.

[11] Basim GB, Adler JJ, Mahajan U, Singh RK, Moudgil BM. Effect of particle size of chemical mechanical polishing slurries for enhanced polishing with minimal defects. J Electrochem Soc. 2000;147:3523-8.

[12] Bielmann M, Mahajan U, Singh RK. Effect of particle size during tungsten chemical mechanical polishing. Electrochem Solid St. 1999;2:401-3.

[13] Wang YG, Zhao YW, Li XF. Modeling the effects of abrasive size, surface oxidizer concentration and binding energy on chemical mechanical polishing at molecular scale. Tribol Int. 2008;41:202-10.

[14] Fu GH, Chandra A, Guha S, Subhash G. A plasticity-based model of material removal in chemical-mechanical polishing (CMP). IEEE Trans Semiconduct Manufact. 2001;14:406-17.

[15] Zhou Y, Pan GS, Shi XL, Zhang SM, Gong H, Luo GH. Effects of ultra-smooth surface atomic step morphology on chemical mechanical polishing (CMP) performances of sapphire and $\mathrm{SiC}$ wafers. Tribol Int. 2015;87:145-50.

[16] Qin K, Moudgil B, Park CW. A chemical mechanical polishing model incorporating both the chemical and mechanical effects. Thin Solid Films. 2004;446:277-86.

[17] Lu Z, Lee SH, Babu SV, Matijevic E. The use of monodispersed colloids in the polishing of copper and tantalum. J Colloid Interface Sci. 2003;261:55-64.

[18] Wang X, Kim SH, Chen C, Chen L, He H, Qian L. Humidity dependence of tribochemical wear of monocrystalline silicon. ACS Appl Mater Interfaces. 2015;7:14785-92.

[19] Gräf D. Reaction of water with hydrofluoric acid treated silicon(111) and (100) surfaces. J Vac Sci Technol A. 1989;7:808.

[20] Takahagi T, Nagai I, Ishitani A, Kuroda H, Nagasawa Y. The formation of hydrogen passivated silicon single-crystal surfaces using ultraviolet cleaning and HF etching. J Appl Phys. 1988;64:3516.

[21] Proksch R, Schaffer TE, Cleveland JP, Callahan RC, Viani MB. Finite optical spot size and position corrections in thermal spring constant calibration. Nanotechnology. 2004;15:1344-50.

[22] Yu J, Kim SH, Yu B, Qian L, Zhou Z. Role of tribochemistry in nanowear of single-crystalline silicon. ACS Appl Mater Interfaces. 2012;4:1585-93. 
[23] Luo JF, Dornfeld DA. Effects of abrasive size distribution in chemical mechanical planarization: Modeling and verification. IEEE Trans Semiconduct Manufact. 2003;16:469-76.

[24] He HT, Kim SH, Qian LM. Effects of contact pressure, counter-surface and humidity on wear of soda-lime-silica glass at nanoscale. Tribol Int. 2016;94:675-81.

[25] Fouvry S, Kapsa P. An energy description of hard coating wear mechanisms. Surf Coat Technol. 2001;138:141-8.

[26] Ramalho A, Miranda JC. The relationship between wear and dissipated energy in sliding systems. Wear. 2006;260:361-7.

[27] Yue D, Ma T-B, Hu Y, Yeon J, van Duin AC, Wang H, et al. Tribochemical mechanism of amorphous silica asperities in aqueous Environment: A reactive molecular dynamics study. Langmuir. 2015;31:1429-36.

[28] Marchand DJ, Chen L, Meng Y, Qian L, Kim SH. Effects of vapor environment and counter-surface chemistry on tribochemical wear of silicon wafers. Tribol Lett. 2013;53:365-72.

[29] Katsuki F, Kamei K, Saguchi A, Takahashi W, Watanabe J. AFM studies on the difference in wear behavior between $\mathrm{Si}$ and $\mathrm{SiO}_{2}$ in $\mathrm{KOH}$ solution. J Electrochem Soc. 2000;147:2328-31.

[30] He HT, Qian LM, Pantano CG, Kim SH. Mechanochemical wear of soda lime silica glass in humid environments. J Am Ceram Soc. 2014;97:2061-8.

[31] Dhere SL, Latthe SS, Kappenstein C, Pajonk GM, Ganesan V, Rao AV, et al. Transparent water repellent silica films by sol-gel process. Appl Surf Sci. 2010;256:3624-9.

[32] Katsuki F. Single asperity tribochemical wear of silicon by atomic force microscopy. J Mater Res. 2009;24:173-8.

[33] Pietsch GJ, Chabal YJ, Higashi GS. The atomic-scale removal mechanism during chemo-mechanical polishing of $\mathrm{Si}(100)$ and Si(111). Surf Sci. 1995;331-333:395-401.

[34] Carpick RW, Ogletree DF, Salmeron M. A general equation for fitting contact area and friction vs load measurements. J Colloid Interface Sci. 1999;211:395-400.

[35] Jacobs TD, Carpick RW. Nanoscale wear as a stress-assisted chemical reaction. Nat Nanotechnol. 2013;8:108-12. 
(a)

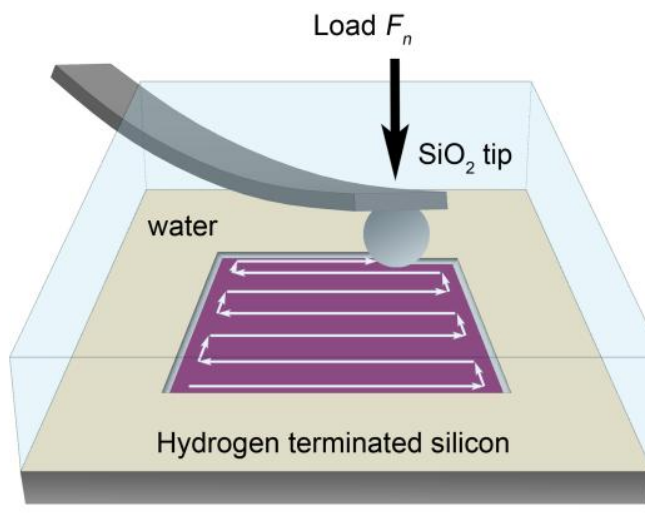

(b)

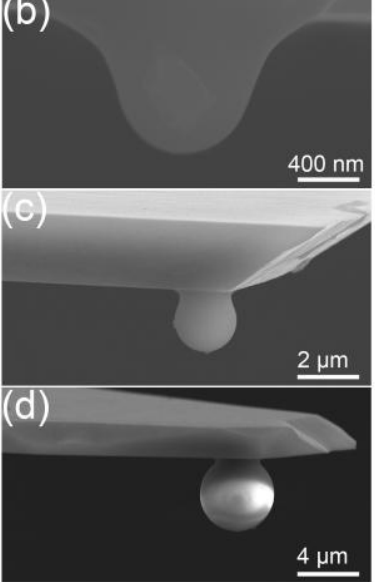

Fig. 1. (a) Illustration of the area-scanning mode for the material removal of silicon surface by AFM in water. The scanning electron microscope images of spherical $\mathrm{SiO}_{2}$ tips with radii $R$ of (b) 0.32 , (c) 1.2 , and (d) $2.8 \mu \mathrm{m}$.

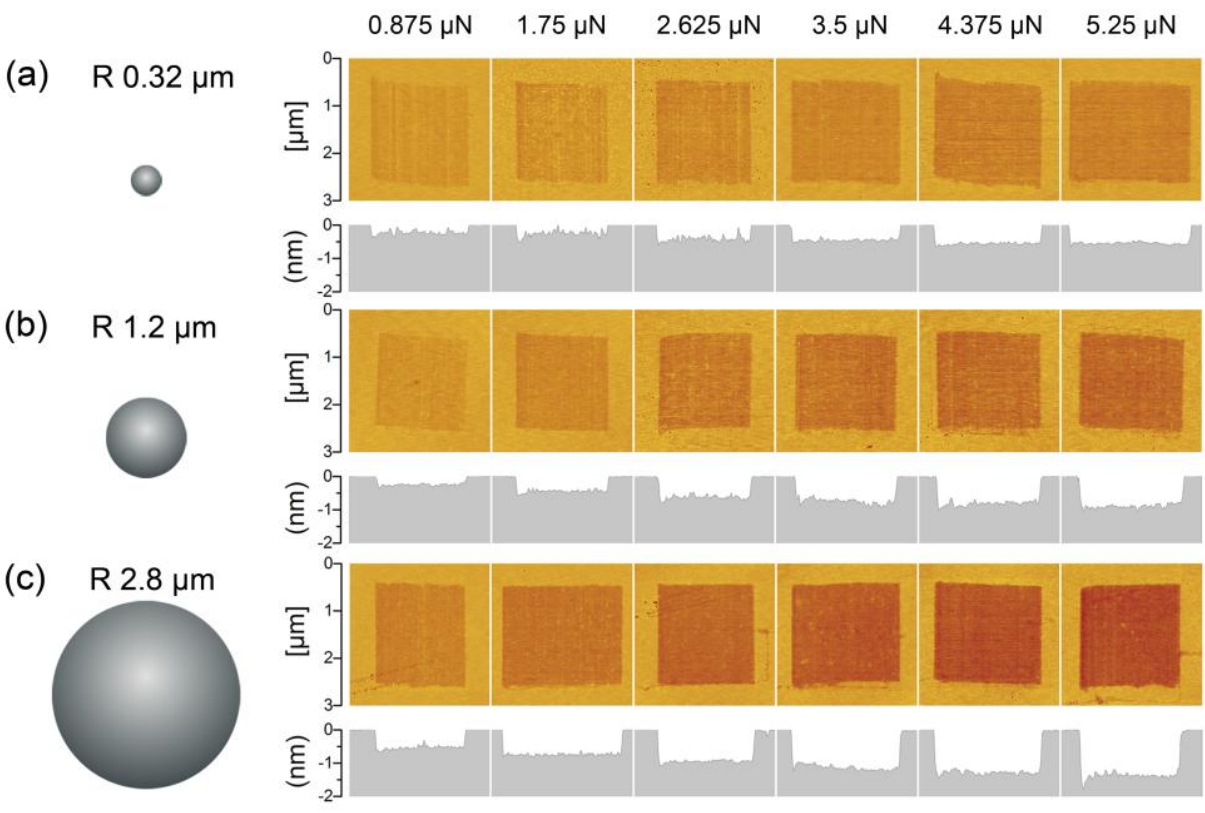

Fig. 2. AFM images and characteristic line profile of wear marks on hydrogen-terminated silicon surface produced by spherical $\mathrm{SiO}_{2}$ tips with various radii $R$ of (a) 0.32 , (b) 1.2 , and (c) $2.8 \mu \mathrm{m}$. The wear tests were performed in water under various applied normal loads. 

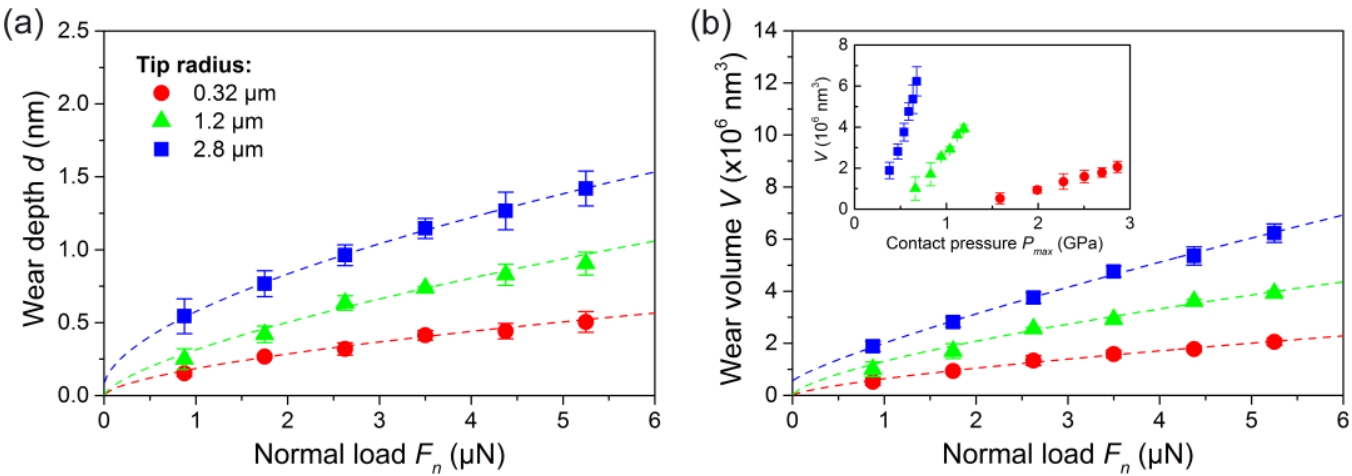

Fig. 3. Dependence of wear depth $d$ (a) and volume $V$ (b) of silicon surface on the applied normal load $F_{n}$ by $\mathrm{SiO}_{2}$ tips with various sizes in water. The inset in (b) shows the variation of wear volume $V$ with the corresponding contact pressure $P_{\max }$.

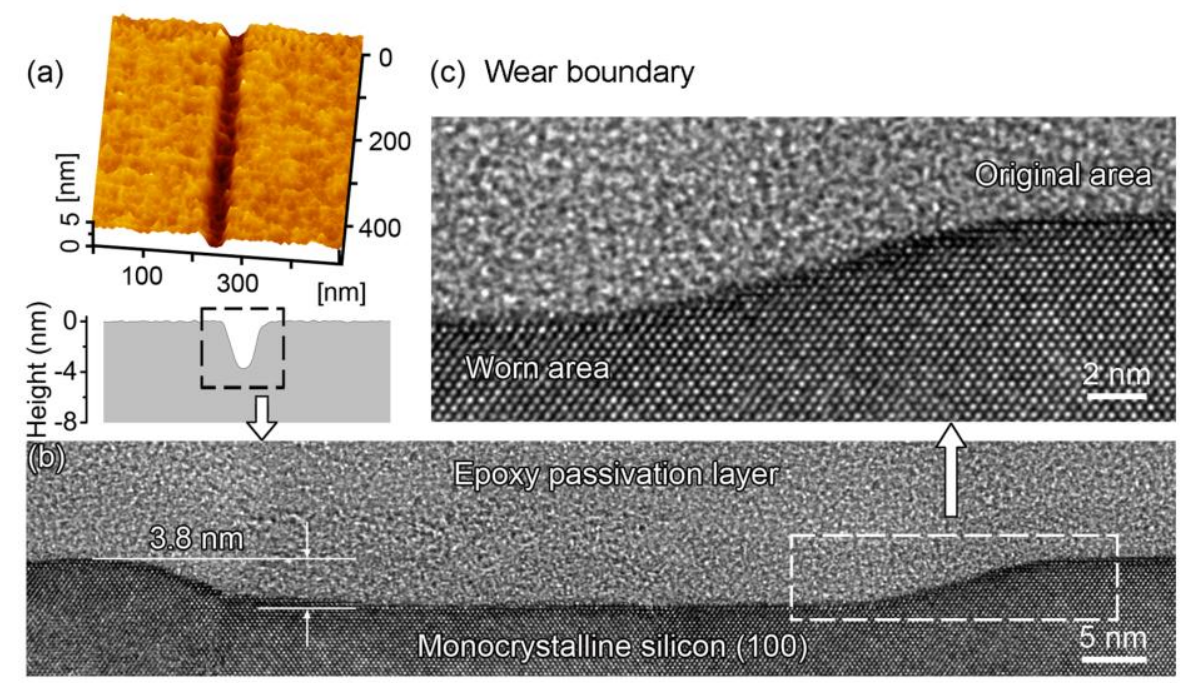

Fig. 4. Characterization of the wear scar on $\mathrm{Si}-\mathrm{H}$ surface derived from the tribochemical wear of a $\mathrm{SiO}_{2}$ tip in water. (a) AFM image and characteristic line profile of the wear scar, (b) HRTEM image of the cross section of the wear scar (dot line in (a)), (c) detailed view of the right boundary of the scratch (dot line in (b)). 

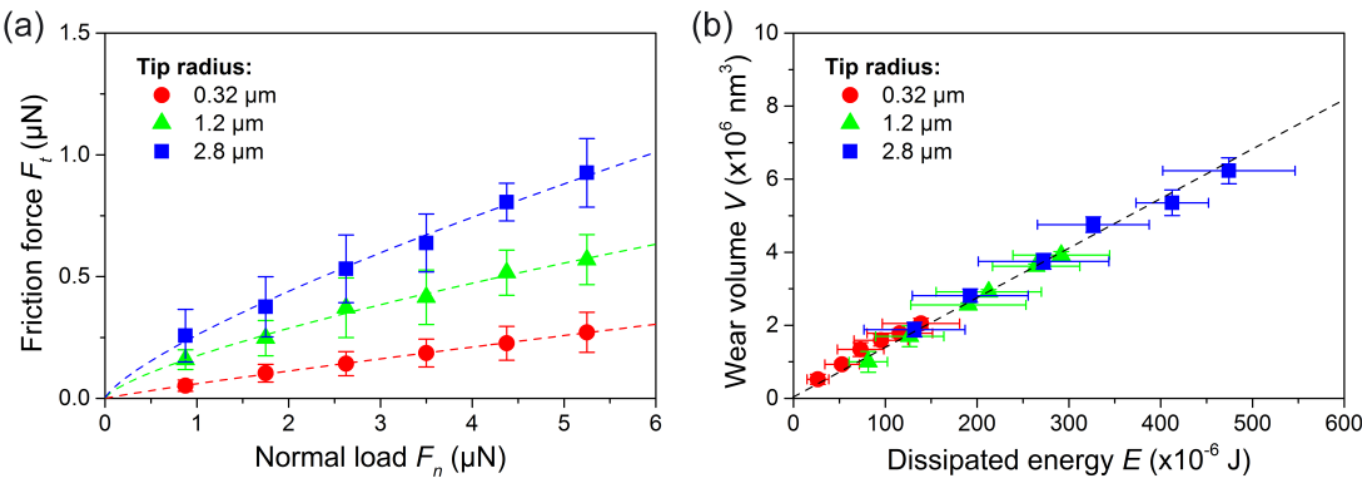

Fig. 6. (a) Friction force $F_{t}$ as the function of the applied load $F_{n}$ for tips with various sizes. (b) Wear volume on silicon surface as a function of the cumulative dissipated energy $E$ during the wear test by $\mathrm{SiO}_{2}$ tips in water.

Fig. 5. Illustration of the tribochemical reaction process occurring at the friction interface of $\mathrm{Si}-\mathrm{H} / \mathrm{SiO}_{2}$ pair in water. 

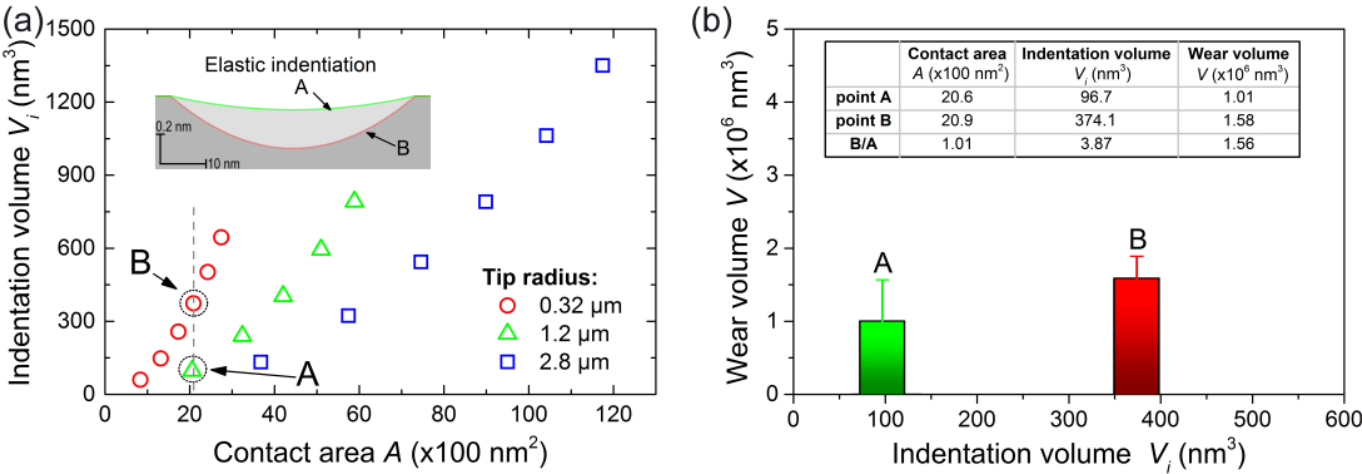

Fig. 7. (a) Indentation volume $V_{i}$ plotted as a function of contact area $A$ at different applied loads with various size tips. Inset shows the elastic indentation profiles of silicon surface at points $\mathrm{A}$ and $\mathrm{B}$, which exhibited nearly equal contact area and were selected to verify the indentation volume model. (b) Dependence of wear volume $V$ on indentation volume $V_{i}$ of $\mathrm{Si}-\mathrm{H}$ surface by $\mathrm{SiO}_{2}$ tips in water. Inner table lists exact values and rising proportions of $A, V_{i}$ and $V$ of points $\mathrm{A}$ and $\mathrm{B}$.

(a)

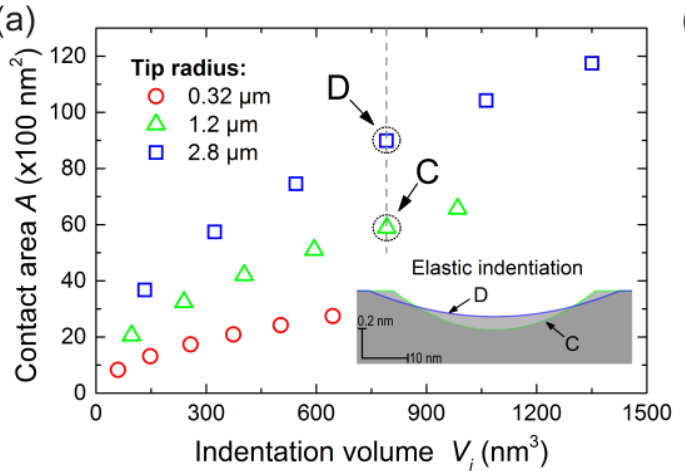

(b)

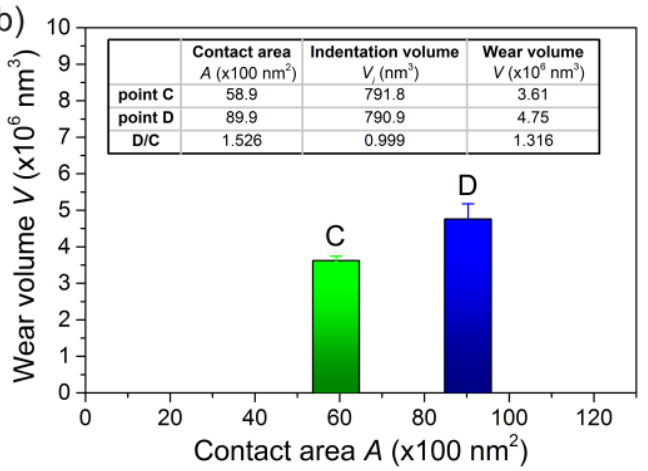

Fig. 8. (a) Contact area $A$ plotted as the function of the indentation volume $V_{i}$ using various tips at different applied loads. Inset shows the elastic indentation profiles of silicon surface at point $\mathrm{C}$ and $\mathrm{D}$, which exhibited the nearly equal indentation volume and were selected to verify the contact area model. (b) Dependence of the wear volume $V$ on the contact area $A$ of $\mathrm{Si}-\mathrm{H}$ surface in water. Inner table lists exact values and rising proportions of $A, V_{i}$ and $V$ of points $\mathrm{C}$ and $\mathrm{D}$. 
